\title{
Young on-road motorcyclists in New Zealand: age of licensure, unlicensed riding, and motorcycle borrowing
}

\author{
Anthony I Reeder, David J Chalmers, John D Langley
}

\begin{abstract}
Objectives-The study aimed to determine the prevalence of unlicensed riding and motorcycle borrowing among young motorcyclists, and to document their perceptions of how they would be affected if the minimum age of licensure were raised.
\end{abstract}

Methods-Motorcycling was investigated as part of the Dunedin Multidisciplinary Health and Development Study, a broad longitudinal study of the health, development, attitudes, and behaviours of a birth cohort. Young motorcyclists, who had ridden on-road during the year before their interview at age 18 years, completed a computer administered questionnaire containing questions about licensure, riding frequency, and motorcycle borrowing.

Results-Of the 217 motorcyclists identified, $36 \%$ were licensed, $54 \%$ had ridden once a month or less frequently, and $72 \%$ had usually ridden a borrowed motorcycle during the one year recall period. Significantly more licensed than unlicensed riders and owners than borrowers reported higher exposure and significantly more licensed than unlicensed riders were owners. Most licensed riders $(86 \%)$ had ridden on public roads before licensure, and many (54\%) thought that they would have been much affected by a higher minimum age of licensure.

Conclusions-More stringent enforcement of existing licensing regulations, tougher penalties for breaching graduated driver licensing restrictions, raising the minimum age for motorcycle licensure, and prohibiting the sale or lending of motorcycles to unlicensed riders are possible injury prevention strategies.

(Injury Prevention 1995; 1: 103-108)

Keywords: motorcycling, driver licensing, enforcement.

Bringing about a reduction in injuries to motorcyclists by the targeting of young riders, has been identified as a national priority for road safety efforts in New Zealand. ${ }^{1}$ For the 10 year period $1979-88$, the 15 to 19 year age group accounted for $35 \%$ of motorcycling traffic fatalities and $43 \%$ of hospital admissions for motorcycling traffic injuries. ${ }^{2}$ This age group, however, travelled only $9 \%$ of the estimated total distance ridden annually by motorcyclists on public roads. ${ }^{3}$ For 15 to 19 year old males, motorcycling traffic injuries represented $21 \%$ of all injury deaths and $18 \%$ of all injury hospital admissions. ${ }^{2}$ The mortality rate from motorcycle traffic crashes for males in this age group was 25/100000 persons/year and the rate of hospital admissions was 409/100 000 persons/year. ${ }^{4}$ In New Zealand, claims for compensation for injuries are met by the Accident Rehabilitation and Compensation Insurance Corporation (ACC). In 1988 approximately $71 \%$ of ACC compensated claims made by male on-road drivers in the 15 to 19 year old age group were from motorcyclists. ${ }^{5}$ During 1992 , males in this age group were the recipients of $21 \%$ of all paid motorcycling claims to the ACC and had the highest rate of such claims, provisionally calculated at $13 \cdot 75 / 1000$ population. ${ }^{6}$ ACC motorcycling claims expenditure during 1992 totalled in excess of NZ\$50 million (ACC, briefing papers for Motorcycle Safety Task Force meeting; 15 March 1993, Wellington; unpublished).

Risk factors for motorcyclists traffic injuries (that is those sustained on a public highway) ${ }^{7}$ may be categorised as relating to the physical environment, the vehicle itself, the sociocultural environment, or the rider. ${ }^{8}$ Prevention strategies may be similarly categorised. Prevention efforts that focus on modification of the physical environment, such as the removal of hazardous roadside objects and improved traffic management at intersections, clearly have the potential to reduce the risk of injuries. Such modifications, however, have practical limits and there are economic barriers to making substantial changes. Motorcycle design has incorporated a number of improvements aimed at increasing safety (for example, disc braking systems) and crashworthiness (for example, recessed fuel tank filler caps). Nevertheless, the motorcycle remains an inherently unstable vehicle on which riders are particularly vulnerable to injury.

Given that the opportunities for modifying the physical environment and the vehicle have limitations, and that the over-representation of young riders in crashes suggests that rider factors may be involved, there is reason to turn to intervention strategies directed at young riders and their social environment. Preferences among such strategies largely reflect whether it is assumed that it is youthfulness or inexperience that is the primary factor in Prevention Research Unit,
Department of Preventive
and Social Medicine,

University of Otago Medica

School, PO Box 913

Dunedin, New Zealand. 
crashes involving young riders. Those who emphasise the effects of age or immaturity tend to favour reducing exposure through restrictions on motorcycle use ${ }^{9}$ whereas those who emphasise the role of inexperience tend to favour the improvement of knowledge, skills, and protective attitudes and practices, particularly through formal training. ${ }^{1011}$ These two approaches are somewhat in conflict, as strategies aimed at reducing exposure have the effect of also limiting experience. Nevertheless, graduated driver licensing has been promoted as a means whereby exposure to specific hazards (for example, night time riding) can be restricted, while at the same time enabling practical driving skills to be progressively enhanced and monitored. ${ }^{12} 13$

In New Zealand, a three stage graduated driver licensing system was introduced on 1 August $1987 . .^{14} \mathrm{~A}$ learner licence is issued to novice riders who pass tests of eyesight, road code knowledge, and basic handling skills. While the holder of a learner licence, the rider is restricted to a motorcycle with a maximum engine capacity of $250 \mathrm{~cm}^{3}$, must not ride more than $70 \mathrm{~km}$ hour on the open road (maximum speed limit $100 \mathrm{~km} /$ hour), and must carry the licence whenever riding. Pillion passengers must not be carried, there is a curfew on riding between the hours of $10 \mathrm{pm}$ and $5 \mathrm{am}$, and a learner $(\mathrm{L})$ plate must be displayed on the rear number plate. In addition, the driver must not have more than $30 \mathrm{mg}$ of alcohol $/ 100 \mathrm{ml}$ of blood, or more than $150 \mu \mathrm{g} /$ litre of breath. The learner licence is held for six months (reducible by three months if further approved training is undertaken) after which a practical on-road test is administered before a restricted licence is issued. Apart from the $70 \mathrm{~km} /$ hour limit, the same restrictions apply to the holder of a restricted licence, except that passengers may be carried in a sidecar. A restricted licence is held for 18 months (reducible by nine months if an approved course is successfully completed) after which a full licence is issued.

The present paper focuses on three behavioural and social factors that are particularly relevant to young riders: age of licensure, ${ }^{915}$ unlicensed riding, ${ }^{16}$ and motorcycle borrowing. ${ }^{1617}$ These factors are investigated in the context of the frequency of exposure to motorcycling - an important factor when considering injury risk. ${ }^{18}$ The estimate, reported earlier, that riders under the age of 20 years in New Zealand account for only $9 \%$ of total motorcycle distance travelled was obtained from a national travel survey. ${ }^{3}$ Few of this age group were sampled in that survey, however, and the sample was too small $(n=24)$ to estimate a sampling error, thus the finding should be treated with caution.

Although New Zealand has a graduated driver licensing system, it also has a low minimum age for motorcycle licensure (15 years) compared with other developed countries. In most European countries it is 18 years, and some have argued that 20 years would be more appropriate. ${ }^{19}$ In Victoria, Australia, the minimum age for a motorcyclist learner permit is 17 years and $\mathbf{9}$ months, whereas for cars it is
16 years. This age differential is intended to discourage motorcycling, an activity that involves a greater risk of injury than car driving for a given amount of travel, in favour of car driving. ${ }^{18}$ In this context, there is some evidence that experience of car driving reduces the risk of a motorcycle crash among young riders, with those who drive most miles in a car being safest on a motorcycle. ${ }^{20}$ It can be estimated from the national data, ${ }^{4}$ that if the minimum age for motorcycle licensure in New Zealand were to be raised to 17 years, there is the potential to reduce total motorcycling mortality and hospital admissions each by approximately $9 \%$. An increase in age to 18 years could produce an additional reduction of $10 \%$ for fatalities and $8 \%$ for hospitalisations, giving total potential gains of $19 \%$ and $17 \%$, respectively. To achieve such reductions high levels of compliance would be required. Also to be considered is the possibility of a 'flow-on' effect of reduced exposure that could contribute to a reduction in mortality and morbidity among older age groups. This has been demonstrated in the case of raising the minimum age for legal consumption of alcohol to 21 years where lowered rates of drinking in the 18-20 year age group persisted among young adults who had reached the age of legal drinking. ${ }^{21}$

Most studies of licence status among motorcyclists have been concerned with crash victims. One study of fatal motorcycle crashes occurring in a Danish county found that $20 \%$ of riders were unlicensed. ${ }^{19}$ It has been reported in a US study that $46 \%$ of 900 motorcyclists involved in crashes in Los Angeles during 1976-7 were not validly licensed. ${ }^{22}$ A more recent study found that $67 \%$ of severely or fatally injured motorcyclists identified from official records in California were unlicensed. ${ }^{16}$ Furthermore, that study reported that the youngest motorcyclists had the lowest licensure rates. Among those under 20 years of age, only $18 \%$ were licensed. A study based on hospital admission data for the Australian state of Victoria indicated that not having a valid licence was associated with more severe crash outcomes. ${ }^{23}$ In New Zealand, $11 \%$ of all motorcyclists receiving alcohol breath screening tests during 1991 were found to have been disqualified from driving a motorcycle, and a further $32 \%$ either had no valid licence or failed to produce one. ${ }^{24}$ As none of the above studies provide data on the licence status of the motorcyclist population, it cannot be concluded that unlicensed riders are over-represented in crashes.

Previous research suggests that many young riders borrow motorcycles. In one report, 39\% of motorcyclists involved in serious or fatal crashes in California were borrowers. ${ }^{16}$ Among riders under 25 years the proportion was $63 \%$. Of students with motorcycles registered with the University of North Carolina at Chapel Hill, $65 \%$ under the age of 21 years reported lending their motorcycle. ${ }^{17}$ It was surmised that this lending would be to borrowers of a similar age. It was calculated that borrowers had a ninefold greater risk of involvement in officially recorded crashes compared with owners when 
estimated distance travelled was taken into account. In addition, official records indicated that borrowers involved in single vehicle crashes were significantly more likely than owners to have lost control while turning and, in two vehicle crashes, significantly more likely to have been charged with a traffic violation than owners. It was hypothesised that these were consequences of borrowers having difficulty handling borrowed motorcycles. Lack of familiarity with the motorcycle ridden was a risk factor for hospitalised motorcyclists in Victoria, Australia. ${ }^{23}$

One could conclude from the literature that unlicensed riding and motorcycle borrowing, considered in the context of exposure and minimum age of licensure, may be important risk factors for crashes. No studies could be identified, however, that investigated these factors among large samples of young riders selected in a manner that would not tend to exclude the unlicensed and non-owners. Furthermore, despite the fact that knowledge about target populations is crucial for designing interventions, little is known about these factors in relation to the young New Zealand motorcyclists at greatest risk. The aim of the present study was to investigate these issues among young riders identified from a birth cohort already enrolled in a longitudinal study.

\section{Methods}

THE COHORT

The participants in this study were members of a birth cohort enrolled in the Dunedin Multidisciplinary Health and Development Study, a longitudinal study of health, development, attitudes, and behaviour. The method of selection and the composition of this cohort have been described fully elsewhere..$^{25}$ In summary, cohort members were drawn from all children born at Dunedin's only obstetric hospital, between 1 April 1972 and 31 March 1973. The cohort included all children born during that year whose mothers had resided in the Dunedin Metropolitan area and who were known to be still resident in the province of Otago when the children were 3 years of age. Of the 1139 children eligible at age 3 years, 1037 were followed up and assessed within a month of their third birthday. The cohort is somewhat biased socioeconomically and ethnically towards the advantaged, and those of European descent, ${ }^{25}$ but the full socioeconomic spectrum is represented. ${ }^{26}$

At age 18 years, $876(85 \%)$ of the surviving 1027 cohort members attended the assessment unit and completed an interview about their

Table 1 Frequency of on-road motorcycling during the past year, by licence status; results are number $(\%)$

\begin{tabular}{lcll}
\hline Frequency & Licensed & Unlicensed & Total \\
\hline Less than once a month & $17(21)$ & $78(57)$ & $95(44)$ \\
About once a month & $6(8)$ & $17(12)$ & $23(10)$ \\
Two to four times a month & $9(11)$ & $25(18)$ & $34(16)$ \\
More than once a week, but less than once a & $22(28)$ & $13(9)$ & $35(16)$ \\
$\quad$ day & $25(32)$ & $5(4)$ & $30(14)$ \\
Once a day or more & $79(100)$ & $138(100)$ & $217(100)$ \\
Total & & & \\
\hline
\end{tabular}

transportation behaviour. Of the 151 not completing a full assessment, 61 (mostly Australian residents) completed a short interview, and 47 provided only limited personal background information. Telephone contact with a relative established that another 17 were still alive but unable to attend for assessment, 13 refused any participation, four specifically refused the transportation interview, and four could not be traced. In addition, five cohort members had severe intellectual disabilities that precluded their full participation.

Of the 876 cohort members who completed the interview, 444 indicated some exposure to motorcycling, either on- or off-road, during the one year period before interview. These riders were eligible to complete a detailed motorcycling computer questionnaire. For a variety of reasons (for example time constraints), however, full data were not available for 19 individuals. Of the 425 riders who completed the questionnaire, 217 (41 females and 176 males) reported some motorcycling on public roads during the one year recall period. The results reported here are based on this group of motorcyclists.

\section{SOURCES OF INFORMATION}

After written consent was obtained, structured questionnaires were administered during confidential interviews conducted at the assessment unit by trained staff during 1990 and 1991. Copies of these questionnaires are available from the corresponding author.

\section{Results}

Of the 217 motorcyclists, $36 \% \quad(n=79,71$ males and eight females) held a valid motorcycle licence, $44 \% \quad(n=35)$ of whom held a learner licence, $22 \%(n=17)$ a restricted licence, $30 \%(n=24)$ a full graduated licence, and $4 \%(n=3)$ had a licence obtained before the graduated driver licensing system. Only $5 \%$ of the 217 motorcyclists held a motorcycle driving licence exclusively; whereas $76 \%$ held a licence to drive a car. Some motorcyclists, may have held a motorcycle licence throughout the recall period whereas others may have been licensed for only part of that time.

Exposure to motorcycling was first measured in terms of the number of riding occasions reported for the one year period before interview. The frequency distribution of this exposure is shown in table 1 . Licensed motorcyclists reported significantly more frequent exposure than their unlicensed counterparts $\left(\chi^{2}=55.68 ; 4 \mathrm{df} ; \mathrm{p}<0.001\right)$. Also measured was exposure based on the estimated distance driven during the week immediately before interview. Some exposure during this one week period was reported by 47 riders. The reported distance ranged from $1 \mathrm{~km}$ to $550 \mathrm{~km}$, with a mean of $103 \mathrm{~km}$ and a mode of $20 \mathrm{~km}$. A broader range of distances and a greater mean distance were found for licensed $(n=30)$ than unlicensed $(n=17)$ riders; however, the Wilcoxon rank sum test indicated that this difference did not reach statistical significance $(p=0.27)$. 
The 76 motorcyclists who had obtained a licence under the graduated driver licensing system were asked if they had ridden a motorcycle on a public road before they held a learner licence. The distribution of their responses is shown in table 2 . When four riders who were unsure if they had ridden before licensure were excluded, $86 \%(n=62)$ of the remaining 72 licensed motorcyclists had ridden on-road before they were licensed to do so. Of these 62, $92 \%$ had ridden at least once for reasons other than to attend a motorcycle training school.

All licensed riders were asked 'How much would it have affected you if motorcycle (or moped) licences were not available to anyone until after they were 17 years of age?' Their responses are shown in table 3 in relation to reported motorcycling exposure during the year before interview. Two exposure groups were formed for this and subsequent analyses by collapsing the original categories shown in table 1. Riders in the three lowest exposure categories comprised a 'low exposure' group and those in the two highest exposure categories a 'high exposure' group. More riders who reported high rather than low exposure indicated that they thought they would have been affected 'a lot' $\left(\chi^{2}=6 \cdot 22 ; 2\right.$ df; $\left.p=0.045\right)$.

Of the 136 riders without motorcycle licence, $56 \%$ intended to apply for one and 36\% $(n=49)$ did not. Although a greater proportion of those who reported high rather than low exposure expressed an intention to apply, this difference did not reach statistical significance $\left(\chi^{2}=3.22 ; 1 \mathrm{df} ; \mathrm{p}=0.073\right)$. Ten riders who were unsure of their intentions were excluded from this analysis.)

All motorcyclists were asked who owned the motorcycle that they had ridden most often during the recall period. Their responses are shown in table 4. Significantly more licensed than unlicensed motorcyclists indicated that they were the registered owner $\left(\chi^{2}=51 \cdot 17\right.$; $1 \mathrm{df} ; \mathrm{p}<0.001)$ and significantly more registered motorcycle owners than borrowers reported high rather than low exposure $\left(\chi^{2}=46.70 ; 1 \mathrm{df} ; \mathrm{p}<0.001\right)$.

\section{Discussion}

The results of the present study are likely to be conservative for two reasons. First, a socioeconomically advantaged cohor $\mathrm{t}^{25}$ may provide an underestimate of motorcycle use because motorcycling is associated with lower socioeconomic status among young New Zealanders. ${ }^{27}$ Second, it is known that individuals with more adverse personal characteristics are less likely to be followed up in longitudinal studies, ${ }^{28}$ thus, the prevalence of these characteristics may be underestimated. Nevertheless, this bias should have been minimised in the present study because of low attrition, thus providing a sample that included, for example, unlicensed riders.

The research was based entirely on self report because in such a large scale study involving many factors it was not possible to use independent confirmation. Nevertheless, self report can provide valid and reliable in-
Table 2 Frequency of on-road motorcycling before licensure reported by current graduated licence holders; results are number $(\%)$

\begin{tabular}{lc}
\hline Frequency & Those reporting \\
\hline Not at all & $10(13)$ \\
Only going to skills course & $5(7)$ \\
One to five times & $26(34)$ \\
Five to 10 times & $9(12)$ \\
More than 10 times & $22(29)$ \\
Unsure how many times & $4(5)$ \\
Total & $76(100)$
\end{tabular}

Table 3 Licensed riders: perception of the effect on self of raising the minimum age of licensure to age 17 years, by exposure group; results are number $(\%)$

\begin{tabular}{llcl}
\hline & \multicolumn{2}{l}{ Exposure group } & \\
\cline { 2 - 3 } Amount affected & High & Low & Total \\
\hline A lot & $31(66)$ & $12(37)$ & $43(54)$ \\
A little & $11(23)$ & $14(44)$ & $25(32)$ \\
Not at all & $5(11)$ & $6(19)$ & $11(14)$ \\
Total & $47(100)$ & $32(100)$ & $79(100)$ \\
\hline
\end{tabular}

Table 4 Registered ownership of the motorcycle ridden on-road most frequently, by licence status; results are number $(\%)$

\begin{tabular}{lcll}
\hline Registered owner & Licensed & Unlicensed & Total \\
\hline Male friend & $10(13)$ & $68(49)$ & $78(36)$ \\
Respondent (self) & $45(57)$ & $16(12)$ & $61(28)$ \\
Other males & $8(10)$ & $24(17)$ & $32(15)$ \\
Father & $13(16)$ & $13(9)$ & $26(12)$ \\
All females & $3(4)$ & $10(7)$ & $13(6)$ \\
Not sure & 0 & $7(5)$ & $7(3)$ \\
Total & $79(100)$ & $138(99)^{\star}$ & $217(100)$
\end{tabular}

*Due to rounding.

formation, although socially desirable behaviour may tend to be exaggerated and socially undesirable behaviour minimised. ${ }^{29}$ To improve the validity of self report data in the present study we offered assurances of confidentiality, established good rapport by the use of trained interviewers, and concentrated on relatively recent events. ${ }^{30}$

Perhaps the most revealing finding was that while $51 \%$ of the cohort had recently ridden on a motorcycle, less than half of these had driven on-road, and the frequency of their on-road motorcycling was generally low. Even for those who had ridden during the week before the interview, the modal distance travelled was only $20 \mathrm{~km}$. This was a small group, however, and the range of distances travelled varied substantially. Given that the 15 to 19 year age group has among the highest motorcycling mortality and hospital admission rates of any five year age group, ${ }^{4}$ a far greater exposure to risk might have been expected. This discrepancy serves to emphasise the great risk per unit of exposure involved in riding a motorcycle at this age, and prompts a questioning of the appropriateness of motorcycle use for this age group.

Regular use of a motorcycle for transportation was the exception rather than the rule. Moreover, at least twice as many motorcyclists held a car licence as held a motorcycle licence, and few ( $5 \%$ ) held a motorcycle licence exclusively. Thus, as most young motorcyclists 
apparently had at least some access to a car, and were licensed to drive this safer form of transport, few were entirely dependent on a motorcycle for transportation. In light of this, one could argue that the potential gains to be made from reducing motorcycle crashes by raising the minimum age of motorcycle licensure would outweigh the loss of personal mobility for the relatively few riders under this age who ride motorcycles with any frequency. Nevertheless, over half of all licensed riders, and $66 \%$ of those in the high exposure group, said that raising the minimum age of licensure would have affected them 'a lot'. In terms of training for employment, the reduction in the pool of potential employees for the transport industry would be small, ${ }^{1}$ because motorcycles are used for only a limited range of delivery services.

Because $100 \%$ compliance and enforcement would be improbable, however, it is unlikely that the potential gains could be achieved in full. Nevertheless, the introduction of the graduated driver licensing system does not seem to have resulted in any increase in the number of unlicensed motorcyclists involved in crashes ( $R$ McLaren, Land Transport Safety Authority, Wellington, 1992; unpublished data). Although many young people may be discouraged from motorcycle use altogether if the minimum age of licensure were high enough, this could increase their involvement in crashes as car drivers or passengers, bicyclists, or pedestrians. Nevertheless, the evidence suggests that an overall reduction in serious injuries could reasonably be anticipated. ${ }^{15} 3132$ In Victoria, where the minimum age of motorcycle licensure is 17 years 9 months, only $7 \%$ of motorcycling casualties are under the age of 18 years. ${ }^{18}$ If a rise in the minimum age for motorcycle licensure was implemented while the present minimum age for car licensure was maintained, and the graduated driver licensing system for car drivers was strictly enforced, this could significantly reduce motorcycling injuries without increasing car injuries by a similar amount.

The finding that most motorcyclists did not hold a motorcycle licence was not entirely unexpected, given that the pattern of usage was, typically, casual. Nevertheless, any unlicensed riding should be of concern because it subverts the aims of the graduated driver licensing system. In view of our previous lack of knowledge about the proportion of young New Zealand motorcyclists riding without a licence, and their intentions regarding licensure, the findings in these areas are of particular interest. Only $36 \%$ of the 217 motorcyclists reported holding a motorcycle licence. However, the use of a moped by the holder of a full car licence under the age of 25 years is permitted. This has the potential to blur somewhat the distinction between licensed and unlicensed drivers, and may have resulted in some overstatement of the proportion of the latter. Nevertheless, mopeds are relatively uncommon in New Zealand.

Those unlicensed motorcyclists who did not intend to apply for a licence $(36 \%)$ did not ride significantly less frequently than those who did intend to do so. Future on-road motorcycling intentions were unknown, however, and many of those who did not intend to apply for a licence perhaps also did not intend to continue riding. It is likely that, given such an intention, it may not have seemed worth the effort and cost of going through the graduated driver licensing system procedures. Most motorcyclists in the study were casual riders who rode borrowed motorcycles.

Another relevant factor is the perceived likelihood of being apprehended. Cohort members' perceptions at age 13 years of how often traffic officers apprehended unlicensed motorcyclists are of interest. Most $(57 \%)$ thought that it 'sometimes' happened, 23\% thought it 'hardly ever' happened, and only $20 \%$ that it 'usually' happened. ${ }^{33}$ (Similar perceptions of the likelihood of being caught were not investigated at age 18 years.)

A further possible reason for a lack of incentive to apply for a motorcycle licence is that, whereas parents may insist that their children hold a car driver's licence to maintain insurance protection on the family car, there is no similar pressure in relation to motorcycles, particularly if borrowed without parental knowledge. Thus, there may be little compulsion to obtain a licence.

A substantial majority ( $72 \%$ ) of motorcyclists were not the registered owners of the motorcycle that they had driven most frequently during the recall period. This proportion of borrowers is broadly comparable with the level of motorcycle lending $(65 \%)$ found among students under the age of 21 years who had motorcycles registered with the University of North Carolina. ${ }^{17}$ In the present study, a lower frequency of riding was reported by borrowers than by the registered owners of motorcycles. Nevertheless, borrowing should be of concern because borrowers are more likely than owner drivers to be involved in officially recorded crashes, ${ }^{1617}$ and, in two vehicle crashes, are significantly more likely than owners to be charged with a traffic violation. ${ }^{17}$

\section{Conclusions}

Some involvement with motorcycles is relatively common in New Zealand, particularly among young males, and there seems to be little societal commitment to actively discourage motorcycle use by young riders. There is scope, however, not only for continuing to educate the public regarding the risks of motorcycling, but also for promoting strategies to divert young people towards alternative means of recreation and transport that involve far less risk. The present study has identified possible interventions with a potential for reducing the frequency of motorcycling injuries among young riders. First, a higher relative age for motorcycle licensure, compared with car licensure, could make a positive contribution by diverting riders to a safer form of transport where supervision by a fully licensed adult driver is required by law during the early stages of learning to drive. ${ }^{18}$ Furthermore, for those young drivers who subsequently seek motorcy- 
cle licensure, experience of car driving may reduce their motorcycle crash liability, because young motorcyclists who drive most car miles are safest on a motorcycle. ${ }^{20}$ Second, it is clear that in New Zealand there is room for improvement in compliance with the official road safety strategy of restricting activities that place citizens at increased risk. More stringent enforcement of existing legislation could reduce the number of unlicensed motorcyclists in the high risk younger age groups, thereby achieving a reduction in the total exposed population without raising the minimum age of licensure. ${ }^{934}$ The introduction of stronger penalties for breaches of the graduated driver licensing system could also make a contribution. Finally, legislation that prohibited the sale or lending of a motorcycle to someone without a valid licence is one way in which the issue of borrowing could be addressed. ${ }^{16}$

This paper was completed during tenure by the first author of a postdoctoral fellowship of the Health Research Council of New Zealand. General funding for the assessment of the Dunedin Multidisciplinary Health and Development Study (DMHDS) at age 18 years was provided by the Health Research Council of Mental Health. The support of Dr Phil Silva, Director of the DMHDS, is acknowledged. Accident Rehabilitation and Com pensation Insurance Corporation (ACC) funding for the Motorcycle Injury Prevention Research Programme provided support for the collection and analysis of the data on which this paper i based. The support of the ACC and the HRC as joint funders of the Injury Prevention Research Unit (IPRU), Department of Preventive and Social Medicine, University of Otago is acknowledged. Thanks are due to the interviewers Ms Judy Clarke, Ms Maree Drury, Dr Anna Waller and, particularly, to Clarke, Ms Maree Drury, Dr Anna Waller and, particularly, to
Ms Dorothy Begg who was also involved with the design of Ms Dorothy Begg who was also involved with the design of questionnaires. Thanks are also due to Dick Martin and Nicola Walmsley of the Otago University Computing Services Centre for assistance with the computer administered questionnaire. The assistance of Rachael McLaren of the Safer People. and Operator Group, Land Transport Safety Authority, Wellington is also acknowledged. Comments by the ACC reviewers for the Motorcycling Injury Prevention Research Programme were appreciated and have been taken into account. Last, but no active cooperation made this study possible.

1 The Officials Committee on Road Safety. National road safety plan. Wellington: The Officials Committee on Road Safety, 1991.

2 Reeder AI, Chalmers DJ, Langley JD. Adolescent motorcyclists: injury risks, attitudes, behaviours and opportunities for injury prevention. The Officials Committee on road Safety and Road Traffic Safety Council. National road safety seminar; Wellington, New
November 2-4, 1992. Vol 1, 1992: 168-78.

3 Ministry of Transport. New Zealand household travel surve fuly 1989-fune 1990. Traffic research report 43. Welling ton: Traffic Research and Statistics Section, Safety and Standards Branch, Land Transport Division, Ministry of Transport, 1992.

4 Langley JD, Begg DJ, Reeder AI. Motorcycle crashes in New Zealand resulting in death and hospitalisation. II: traffic crashes. Accid Anal Prev 1994: 26: 165-71.

5 Bailey JPM. A study of road accident victims in New Zealand aged 13 to 18. ACC research report 104. Wellington: Policy Development Section, Accident Compensation Corporation, 1988.

6 Accident Rehabilitation and Compensation Insurance Corporation. Injury statistics 1992. Wellington: ACC, 1993.

World Health Organisation. International classification of diseases, 1973 revision. WHO, Geneva, 1975.

8 Haddon W Jnr. Options for the prevention of motor vehicle crash injury. Isr f Med Sci 1980; 16: 45-68.

9 Brown RC, Sanders JM, Schonberg SK. Driving safety and adolescent behavior. Pediatrics 1986; 77: 603-7.
10 Bothwell PW. The problem of motorcycle accidents. The Practitioner 1962; 188: 474-88.

11 Avery JG. Motorcycle accidents in teenage males. A modern epidemic. The Practitioner 1979; 222: 369-80.

12 New Zealand road safety, August 1987. Wellington: Ministry of Transport, 1987.

13 Traffic Injury Research Foundation of Canada. New to the road. Prevention of measures for young or novice drivers. Key findings and implications from an international symposium. Sheraton Halifax Hotel, Halifax, Nova Scotia, February 17-21, 1991.

14 New Zealand Government. Transport (driver's licensing) regulations 1987. Wellington: VR Ward, Government regulations 1987.

15 Laberge-Nadeau C, Maag U, Bourbeau R. The effects of age and experience on accidents with injuries: should the and experience on accidents with injuries: should the licensing

16 Kraus JF, Anderson C, Zador P, et al. Motorcycle licensure, ownership, and crash involvement. Am $\mathcal{f}$ Public Health 1991; 81: 172-6.

17 Barry PZ. The role of inexperience in motorcycle crashes. fournal of Safety Research 1970; 2: 229-39.

18 Parliament of Victoria, Road Safety Committee. Report upon the inquiry into motorcycle safety in Victoria. Melbourne: LV North, Government Printer, 1993.

19 Larsen CF, Hardt-Madsen M. Fatal motorcycle accidents in the county of Funen (Denmark). Forensic Sci Int 1988; 39: 93-9.

20 Taylor MC, Lockwood CR. Factors affecting the accident liability of motorcyclists - a multivariate analysis of survey data. Research report 270 . Behavioural Studies Unit Safety and Transportation Group, Transport and Road Research Laboratory. Crowthorne, Berkshire, UK: Research Laboratory. Crowth

21 O'Malley PM, Wagenaar AC. Effects of minimum drinking age laws on alcohol use, related behaviors and traffic crash involvement among American youth: 1976-1987. F Stud Alcohol 1991; 52: 478-91.

22 Hurt HH Jnr, Ouellet JV, Thom DR. Motorcycle accident cause factors and identification of countermeasures. Volume 1: technical report. Washington, DC: US Department of Transportation, National Highway Traffic Safety Administration, 1981.

23 Haworth N, Ozanne-Smith J, Fox B, Brumen I. Motorcyclerelated injuries to children and adolescents. Report No 56. Melbourne, Australia: Monash University Accident Research Centre, 1994.

24 Ministry of Transport, Land Transport Division, Safety Standards Branch, Traffic Research and Statistics Section. Motor accidents in New Zealand. Statistical statement calendar year 1992. Wellington: Land Transport, 1993.

25 Silva PA. The Dunedin multidisciplinary health and development study: a fifteen year longitudinal study. Perinatal and Paediatric Epidemiology 1990; 4: 76-107.

26 Reeder AI, Feehan M, Chalmers DJ, Silva PA. Some socioeconomic characteristics of a much-studied cohort: the Dunedin multidisciplinary health and development study. New Zealand fournal of Educational Studies 1994; 29: 209-13.

27 White WT, Toomath JB. Motorcyclist exposure to risk of accidents. Motorcycle Safety Foundation. Proceedings of the international motorcycle safety conference. Irvine CA May 18-23, 1980. vol 4, 1980: 1613-38.

28 Cox A, Rutter M, Yule B, Quinton D. Bias resulting from missing information: some epidemiological findings. British fournal of Preventive and Social Medicine 1977; 31: British $131-6$.

29 Harrell AV. Validation of self-report: the research record. In: Rouse BA, Kozel NJ, Richards LG, eds. Self-report methods of estimating drug use: meeting current challenges to validity. NIDA research monograph 57 . Rockville, Maryland: Department of Health and Human Services, National Institute on Drug Abuse, 1985: 12-21.

30 Nurco DN. A discussion of validity. In: Rouse BA, Kozel NJ, Richards LG, eds. Self-report methods of estimating drug use: meeting current challenges to validity. NIDA research monograph 57. Rockville, Maryland: Department of Health and Human Services, National Institue on Drug Abuse, 1985: 4-11.

31 Williams AF, Karpf PL, Zador PL. Variations in minimum licensing age and fatal motor vehicle crashes. Am $\mathcal{f}$ Public Health 1983; 73: 1401-4.

32 Robertson LS. Injuries: causes, control strategies and public policy. Lexington, MA: Lexington Books, 1983.

33 Reeder AI, Chalmers DJ, Langley JD. Motorcycling attitudes and behaviours. I. 12 and 13 year old adolescents. F Paediatr Child Health 1992; 28: 225-30.

34 Robertson LS. Patterns of teenaged driver involvement in fatal motor vehicle crashes: implications for policy choice. f Health Polit Policy Law 1981; 2: 303-14. 